\title{
THE PROPERTY ISSUE IN THE CYPRUS NEGOTIATIONS
}

\author{
AYLA GÜREL - KUDRET ÖZERSAY
}

\section{Introduction}

The property issue has obviously a great political significance: how the rights to properties and housing are to be resolved is regarded by the two Cypriot sides as a major factor that will predetermine the meaning of bizonality, ostensibly a universally accepted principle for a Cyprus settlement. This seems to be what makes the property issue one of the most contentious aspects of the Cyprus conflict

Now, it has been a common complaint that the Annan Plan's property regime was, apart from being extremely complex, widely divergent from either community's demands and from what had been argued for by their leadership during the preceding negotiations. The implication was that it contained arrangements that were largely unforeseen. An even more widespread criticism, linked with the first one, has been that the Plan was a product of 'external forces', by means of which they hoped to impose their own 'solution' on the Cypriots. 
It is of course undeniable that the Annan Plan was ultimately put together by 'others': namely, the relevant UN team of international experts, aided by other international emissaries. On the other hand, one needs to remember that for many decades before that the parties had been negotiating under the sponsorship of the UN with the purpose of finding an agreed settlement of the Cyprus problem. The evolution of the process of talks and the question of how 'related' or 'alien' the Plan's provisions are to all these preceding ideas is therefore interesting and worth investigating.

In what follows we try to do this in the restricted context of the property issue. To provide the setting, a review of each side's position and desired solution is given first, followed by a study of the treatment of the property issue in the main phases of the negotiations after 1974, which, as many see it, culminated in the most recent comprehensive document, the Annan Plan.

\section{The Negotiations}

\section{Before the Ghali Set of Ideas}

During the intercommunal talks from 1975 until the formulation of the 'Ghali Set of Ideas' in the early 1990s, property was not a topic that was explicitly discussed. Rather, property related matters came up in indirect references generally under the following three main headings:

\section{a) Territorial issues}

b) Fundamental Human rights

c) Security

This approach of addressing the property issue indirectly, i.e., under other topics, instead of proposing a specific comprehensive treatment of it, was in fact compatible with the positions of the parties. 
Proposals by the UN

The UN proposals after 1979 generally reaffirmed the basis that had emerged at the high level agreements.

In the period before the Ghali Set of Ideas, at least as significant as the 1977 and 1979 High Level Agreements were the negotiations during 1989, which led to the so-called 'basic principles' for negotiating an overall agreement. Among these were also elements concerning the property issue, summarised in the Secretary General's opening statement concerning the following:

1) Meaning of bizonality

2) The principle of three freedoms

3) Greek Cypriot and Turkish Cypriot displaced persons

a- A territorial adjustment

b- The Rights of the Greek Cypriot and the Turkish Cypriot displaced persons

This was an exploration by the UN of more comprehensive ideas towards a settlement but clearly based on what had emerged during discussions with the two sides. As regards the specific issue of property, a crucial step was made. This was an attempt to clarify the meaning of such fundamental but still highly ambiguous principles as bizonality and three freedoms, as well as to establish a balance in practice between these two apparently conflicting principles.

\section{The Ghali Set of Ideas}

At the beginning of 1992, the two sides' positions on the issues linked with the property issue were still as far apart as ever.

Nevertheless, talks between the two sides were carried on during that year under the auspices of the UN, with the aim of preparing a draft for 'an overall framework agreement on Cyprus'. The result of all this effort was a UN document, which soon became known as 'the Ghali Set of Ideas.' There is no doubt that in many 
respects, and not least as regards the property issue, the Set of Ideas was the progenitor of the Annan Plan of ten years later.

According to this framework, the three freedoms would be safeguarded and applied on the basis of the 1977 high-level agreement (paragraph 48). Whereas the freedom of movement would be exercised without any restrictions from the beginning; the freedom of settlement and the right to property would be implemented after the resettlement process arising from the territorial adjustments had been completed while being regulated by the federated states in a manner to be agreed upon (paragraphs 49-50).

In this draft, the basic principles concerning the displaced persons' property claims that had emerged until then were considerably fleshed out. In fact, the Ghali Set of Ideas was the first such draft that contained a separate section devoted to the matter of property (section IV with heading 'Displaced Persons'). Here, for the first time, the recognition of the property claims (not ownership) of Greek Cypriot and Turkish Cypriot displaced persons was emphasised. At the same time, it was stated that these rights would be dealt with fairly on the basis of a time frame and in accordance with practical regulations based on (a) the 1977 high-level agreement, and (b) the need to ensure social peace and harmony (paragraph 72).

The property arrangements in the Ghali Set of Ideas were meant to be an attempt to find a balance between the human rights norms and the bizonality requirement, in a way compatible with what is common practice in dealing with property rights in conflict situations. This is doubtless a consequence of the reasonable assumption on the part of the UN that only a fair balance between conflicting but legitimate demands could produce an agreed solution to the problem.

\section{The Annan Plan}

The Annan Plan is essentially an expansion of the basic principles that had transpired during the many years of negotiations, particularly those incorporated in the Ghali Set of Ideas. As such, the Annan Plan also contained a property regime complete with detailed 
provisions dealing with properties which were affected as a consequence of events since December 1963.

The origin of certain concepts and techniques that were made use of in devising this property regime go back to the Ghali Set of Ideas and are also similar to those employed in the case of German reunification and in the transformation of the property regime in the eastern European countries during 1990s. These include such schemes as offering alternative property to individuals, excluding properties being used for public purposes from reinstatement, emphasis on returning to one's home town rather than to one's property, issuing of bonds for compensation, and paying compensation rather than reinstating property to owners when the property is significantly developed. On the other hand, some new, and what might perhaps be described as synthetic, techniques have been adopted as well. The idea of 'reinstatement of one-third of the value and one-third of the area of their total property ownership', which has been widely criticised by the Greek Cypriot side, constitutes such an example.

\section{Turkish Cypriot response to the Annan Plan}

Although in the referendum of April 2004, the Turkish Cypriots approved the Annan Plan by a large majority, it must be said that they were generally rather ambivalent about the Plan's property regime. This was of course mainly due to their concern about the potential social and economic impact of this regime given that: (a) a large number of Turkish Cypriots would have had to be relocated; and (b) after the one-third reinstatement to Greek Cypriots and exchange of properties between the two sides, the Turkish Cypriots would still have had to pay a large sum (estimated to be over 4 billion CYP) either as compensation or to purchase Greek Cypriot properties that would be transferred to the Property Board.

An even more daunting point for the Turkish Cypriots was this: the kind of bizonality stipulated in the Annan Plan, particularly in the context of its property provisions, was not what the Turkish Cypriots had argued for. As explained before, based on its understanding of bizonality, the Turkish Cypriot side insisted on resolution of property claims through a global exchange and compensation scheme, which 
meant that neither side's displaced persons would have their properties reinstated.

On the other hand, the fear of the consequences of the Greek Cypriot claims at the ECHR against Turkey could be said to be one of the reasons that brought round a large section of the Turkish Cypriots who were, to say the least, initially sceptical about the Plan's property regime to regard it as a necessary compromise.

\section{Greek Cypriot response to the Annan Plan}

Given the general understanding on the Greek Cypriot side that the right of return and right to property were nonnegotiable human rights, many Greek Cypriots viewed the property regime as a violation of international law and the European conventions. They argued that the restrictions on the claims that could be made in exercising property rights were denying the displaced persons' right to return to their properties and effectively disallowing them from enjoying their properties.

These objections were of course very much in line with the official position of the Greek Cypriot side all along: right to property is a basic human right and therefore cannot be compromised. In the minds of its defenders, this position was repeatedly and clearly shown to be the right one by the numerous ECHR decisions on property related cases against Turkey.

Moreover Cyprus-ran by a wholly Greek Cypriot administration-was soon to accede to the European Union. Once there, the struggle to get Turkey to respect the Greek Cypriot basic human right to properties in the north could be continued under much better conditions, especially given Turkey's own EU membership aspirations. Not surprisingly, all this helped to enhance the belief on the Greek Cypriot side that a settlement closer to its ideal solution was now a true possibility, much more than it has ever been before. 


\section{Conclusion}

The Annan Plan was the most comprehensive settlement document ever produced, dealing with every possible aspect of the Cyprus problem. Of course, developments outside of Cyprus did play a significant role in creating the circumstances that contributed to the making of this Plan: Security Council resolution 1250 (1999), the Greek-Turkish rapprochement, the European Union factor, etc. Nevertheless, none of this should be seen as contrary to the fact that the Plan is a serious and thoughtful attempt to generate a workable compromise solution bearing in mind all the agreed principles and parameters the two sides had reached since at least 1977, and all the useful ideas worked out during the many years of negotiations taking into account the legitimate concerns and sensitivities of both sides.

It is in this light that the property regime in the Plan should be considered. This is not a regime that was popped out of the blue and inflicted on the 'unsuspecting' Cypriots. It was built on basic principles, concepts and techniques that were largely developed in the process of intercommunal talks. Therefore it cannot be reasonably viewed by either side as 'unforeseen' in any way.

On the other hand, the Plan's property regime is certainly not Holy Writ that is infallible and therefore unamendable. In any case this is not the real question. It should not be forgotten that what really matters here is to achieve a sustainable equilibrium between the universal principle of human rights and the most fundamental principle of international law, namely the principle of international peace and security.

In this context, one needs to properly understand the essence and the boundaries of the right to property. Practices that involve loss of or limitation on property ownership under certain conditions and after payment of compensation are commonly accepted as legitimate in international law, provided they are done for protecting public interest, including ensuring 'civil peace' or removal of 'inequalities'. In fact, such interventions are explicitly recognised in Protocol No. 1 of the European Convention of the Protection of Human Rights provided this is done in the 'public interest' and in accordance with the 'general interest'. 
Finally, one must remember that just as upholding human rights is a goal of international law, so is protecting international peace and security. There is little doubt that achieving a settlement in Cyprus should serve the latter as well as the public and general interest on the island. The UN's attempt to establish a balance between the individual's right to property and the principle of bizonality in a Cyprus settlement should be understood in this light.

It is clear that so far the notion of compromise has not been given much serious consideration in either of the two Cypriot communities. Above all, compromise is something neither side seems to be willing to enter into. As explained before, regarding the property issue, the Greek Cypriot side has always striven for a solution strictly conforming to the human rights norms, while for the Turkish Cypriot side any solution must be firmly based on the bizonality requirement. Accordingly, each side's bargaining position has been formulated so as to obtain the maximum of what constitutes the 'ideal solution' for that side. What is more, on both sides this 'ideal solution' has been widely propounded to the public as the sole 'correct', 'just', 'realistic', 'lasting', 'acceptable', etc, solution. Not only that. It has also been portrayed as realistically attainable, without much concern as to how disastrous this would almost certainly be for the prospects of reaching an agreement. In fact, it is hardly an exaggeration to say that, instead of participating in the official reconciliatory objective of the UN negotiation process, the two sides have come to regard the UN primarily as a forum in which they can continue their own parochial conflict.

The two Cypriot sides, if they are both seeking an agreed settlement rather than each trying to get a victory for itself, both needs to bear in mind that international law accepts neither suppression of basic human rights nor human rights without limits. It is clear that no agreement can be reached by the two sides in Cyprus without the Turkish Cypriot side fully realising that displaced persons' right to property cannot be regulated to the extent of denying it, and without the Greek Cypriot side relinquishing the obviously problematic notion that this right can in no way be restricted. This condition has so far been seriously lacking in Cyprus. 